\title{
Effect of combining epidermal growth factor receptor inhibitors and cisplatin on proliferation and apoptosis of oral squamous cell carcinoma cells
}

\author{
SAYAKA TAKAOKA, MASAYASU IWASE, MAKIKO UCHIDA, SAYAKA YOSHIBA, GEN KONDO, \\ HITOSHI WATANABE, MASARU OHASHI, MASAO NAGUMO and SATORU SHINTANI \\ Department of Oral and Maxillofacial Surgery, Showa University School of Dentistry, \\ 2-1-1 Kitasenzoku, Ota-ku, Tokyo 145-8515, Japan
}

Received January 31, 2007; Accepted March 9, 2007

\begin{abstract}
Epidermal growth factor (EGF) is known to be involved in the proliferation and metastasis of squamous cell carcinoma (SCC), suggesting that the EGF receptor (EGFR) must also contribute to SCC development. In combination with conventional anti-cancer drugs, agents that block EGFR may represent an efficient means of inhibiting proliferation and inducing apoptosis in SCC cells. We investigated the effects of combining an anti-EGFR monoclonal antibody (C225) or an EGFR-selective tyrosine kinase inhibitor (AG1478) with the conventional anti-cancer drug cisplatin on the oral SCC (OSCC) cell lines NA and Ca9-22. We detected constitutive expression of EGFR on the cell membranes of both cell lines. OSCC cell proliferation was inhibited by C225, AG1478 and cisplatin in a dose-dependent manner. The combination of $\mathrm{C} 225$ or AG1478 with cisplatin at concentrations $<\mathrm{IC}_{50}$ synergistically inhibited cell proliferation and induced apoptosis in these cells. Furthermore, treatment with C225 or AG1478 OSCC reduced phosphorylation of EGFR and Akt, as well as Bad. EGFR inhibitors down-regulated expression levels of the anti-apoptotic proteins cellular IAP-1 (cIAP-1), X-linked IAP (XIAP), Bcl-2 and Bcl-xL, whereas those of the proapoptotic proteins Bax and Bak were up-regulated, and neither cIAP-2 nor survivin were affected. Therefore, EGFR inhibitors can provide partial regulation of cisplatin-mediated apoptosis in OSCC cells by modulating expression of cIAP-1, XIAP, Bcl-2, Bcl-xL, Bax and Bak. These results suggest that EGFR inhibitors may represent a novel strategy for overcoming resistance to cisplatin-mediated apoptosis via the phosphatidylinositol 3-kinase/Akt pathway.
\end{abstract}

Correspondence to: Dr Masayasu Iwase, Department of Oral and Maxillofacial Surgery, Showa University School of Dentistry, 2-1-1 Kitasenzoku, Ota-ku, Tokyo 145-8515, Japan

E-mail: iwase@senzoku.showa-u.ac.jp

Key words: apoptosis, cisplatin, epidermal growth factor receptor inhibitor, oral squamous cell carcinoma, proliferation

\section{Introduction}

The survival rate of patients with oral squamous cell carcinoma (OSCC) remains low despite advances in diagnosis and treatment (1). OSCC usually develops in carcinogen-exposed areas of the epithelium, likely resulting from an accumulation of cellular and genetic alterations that leads to aberrant expression of proteins involved in cell growth regulation (2). Blockage or functional modification of these proteins may impede or delay development of cancer.

Chemotherapy is the mainstay of treatment for patients with recurrent/metastatic OSCC and may be used alone or in combination with other chemotherapeutic agents or radiation therapy $(3,4)$. Cisplatin is the most important therapeutic agent; however, it exhibits hematological, neuro-, nephroand oto-toxicity, and thus attempts to deliver high doses or dose-intensified cisplatin have been largely unsuccessful (5). Drug resistance represents an additional challenge to cisplatinbased chemotherapy. Cisplatin interacts with cellular nucleophiles, resulting in inter- and intra-strand DNA cross-linking as well as DNA-protein and RNA cross-links (6). Cisplatininduced apoptosis is generally considered to result from its ability to damage DNA (7); chemotherapeutic agents that use this strategy are dependent upon activation of the mitochondrial pathway via intact caspase cascades (8-10). This apoptotic pathway is regulated by pro- and anti-apoptotic members of the Bcl-2 family (10); once activated, certain caspases might also be controlled by proteins belonging to the inhibitor of apoptosis protein (IAP) family (9). Alterations in abundance of such apoptosis-regulated proteins may contribute to cellular resistance to chemotherapeutic agents $(9,10)$.

An attractive strategy for improving treatment responses is the combination of standard chemotherapy and specific molecular-targeted therapy, as the latter offer a means for directly targeting the tumor without exacerbating the side effects associated with standard treatment (5). Epidermal growth factor receptor (EGFR) plays an important role in the regulation of cell proliferation, differentiation, development and oncogenesis $(11,12)$. Activation of downstream effectors of the EGFR signaling pathway can also lead to cell proliferation and tumor growth, as well as progression of invasion and metastasis (13). In many types of tumor and in most SCCs (14), EGFR is expressed at high levels and it is associated with an 
adverse impact on survival $(15,16)$. Thus, EGFR has been identified as an important target for cancer therapy and in recent years there has been a considerable effort to identify EGFR inhibitors such as monoclonal antibodies (mAbs) directed against the external ligand binding domain $(17,18)$ or small molecule tyrosine kinase (TK) inhibitors $(19,20)$. Both in vitro and in vivo studies on SCCs have found additive/ cooperative effects from combinatorial treatments using antiEGFR mAb or EGFR-TK inhibitor with other chemotherapeutic agents such as cisplatin, or with radiotherapy (21-25). However, the molecular mechanisms underlying tumor remission under these combined therapies remain largely unknown. In order to identify novel treatment strategies for the management of SCC patients, we urgently require a clearer understanding of the mechanisms at play.

In this study, we investigated anti-tumor activation in OSCC cells in vitro using a combinatorial treatment of EGFR inhibitors and cisplatin. We also examined whether or not EGFR inhibitors can regulate pro- and anti-apoptotic proteins such as the members of the Bcl-2 and IAP families. We observed that EGFR inhibitors enhance cisplatin-mediated apoptosis via up-regulation of pro-apoptotic proteins and down-regulation of anti-apoptotic proteins.

\section{Materials and methods}

Reagents. DMEM and FBS were obtained from Gibco BRL (Gaithersburg, MD). AG1478 and C225 were purchased from Calbiochem (San Diego, CA) and cisplatin from the Sigma Chemical Co. (St Louis, MO). The MEBCYTO apoptosis kit (employing FITC-conjugated annexin V) was purchased from MBL (Nagoya, Japan). We used antibodies against the following: Bax, cIAP-1, cIAP-2 and XIAP (R\&D Systems Inc., Minneapolis, MN); Bak (Stressgen Biotechnology, Victoria, Canada); Bcl-2, Bcl-xL and survivin (Santa Cruz Biotechnology, Santa Cruz, CA); and EGFR, phospho-EGFR, Akt, phospho-Akt, Bad and phospho-Bad (Upstate Biotechnology, Lake Placid, NY). Control antibodies were obtained from Pharmingen (San Diego, CA). All other chemicals used were of analytical grade.

Cell culture. The human OSCC cell lines NA and Ca9-22 were grown as adherent monolayers. Both cell lines were established from SCC of the oral cavity. Cells were maintained in DMEM supplemented with $10 \%$ heat-inactivated FBS, 2 mM Lglutamine and antibiotics $(100 \mathrm{U} / \mathrm{ml}$ penicillin and $100 \mu \mathrm{g} / \mathrm{ml}$ streptomycin) at $37^{\circ} \mathrm{C}$ in a humidified atmosphere of $5 \% \mathrm{CO}_{2}$.

Assessment of EGFR receptor expression. We performed indirect immunofluorescence analyses of cell surface EGFR expression in OSCC cells $\left(1 \times 10^{6}\right.$ cells $\left./ \mathrm{ml}\right)$, which were treated with a saturating concentration of anti-EGFR mAb for $40 \mathrm{~min}$. After washing twice with PBS cells were incubated for $30 \mathrm{~min}$ at $4^{\circ} \mathrm{C}$ with anti-mouse IgG-FITC-conjugated secondary $\mathrm{Ab}$ dissolved in PBS containing $0.1 \%$ BSA and $0.1 \%$ sodium azide. Cells were washed again with PBS and fixed with $1 \%$ paraformaldehyde in PBS. Simultaneous negative control staining was performed without primary Ab. Stained cells were analyzed using a FACScan flow cytometer and CellQuest software (Becton Dickinson Co., Mountain View, CA).
Proliferation assay. The cytotoxic effect of treatment with EGFR inhibitors and cisplatin on OSSC cells was evaluated using a proliferation assay, in which proliferation was determined using a Cell Counting Kit-8 (Wako, Tokyo, Japan) that labeled cellular DNA with a fluorescent reagent (26). In brief, cells ( $1 \times 10^{4} /$ well) were seeded into 96 -well plates and cultured for $24 \mathrm{~h}$ to allow adherence. The cells were then incubated for $24 \mathrm{~h}$ at $37^{\circ} \mathrm{C}$ with a range of concentrations of each of the following agents: C225 (0-16 nM), AG1478 $(0-32 \mu \mathrm{M})$ and cisplatin $(0-20 \mu \mathrm{M})$. Alternatively, cells were treated with cisplatin $(5 \mu \mathrm{M})$ and either $\mathrm{C} 225(4 \mathrm{nM})$ or AG1478 $(8 \mu \mathrm{M})$. Following incubation, $10 \mu \mathrm{l} \mathrm{WST-8} \mathrm{(induced}$ by the generation of formazan) was added to each well and incubated for a further $45 \mathrm{~min}$ at $37^{\circ} \mathrm{C}$, after which the $\mathrm{A}_{450}$ was measured in a microplate reader.

Apoptosis assay. Annexin V-FITC binding was used as a sensitive method for quantifying apoptosis and was performed as described previously $(27,28)$. OSCC cells $\left(1 \times 10^{4} /\right.$ well $)$ were seeded into 96-well plates and cultured for $24 \mathrm{~h}$ to allow adherence, then incubated with C225 (4 nM) or AG1478 $(8 \mu \mathrm{M})$ for $24 \mathrm{~h}$. Alternatively, cells were preincubated with or without C225 $(4 \mathrm{nM})$ or AG1478 $(8 \mu \mathrm{M})$ for $2 \mathrm{~h}$, then exposed to cisplatin $(5 \mu \mathrm{M})$ for $24 \mathrm{~h}$ and harvested. Specific binding of annexin V-FITC was performed by incubating the cells for $15 \mathrm{~min}$ at room temperature in binding buffer (10 mM HEPES, $140 \mathrm{mM} \mathrm{NaCl}, 2.5 \mathrm{mM} \mathrm{CaCl}_{2}, \mathrm{pH}$ 7.4) containing a saturating concentration of annexin V-FITC, according to the manufacturer's protocol. Following incubation, cells were pelleted and analyzed using a FACScan flow cytometer and Cell Quest software (Becton Dickinson Co.).

Western blot analysis. Western blot analysis was used to direct expression of EGFR, p-EGFR, Akt, p-Akt, Bad, p-Bad, Bax, Bak, Bcl-2, Bcl-xL, cIAP-1, cIAP-2, XIAP and survivin. OSCC cells $\left(1 \times 10^{7}\right.$ cells $\left./ \mathrm{ml}\right)$ were incubated with or without $\mathrm{C} 225(4 \mathrm{nM})$ or AG1478 $(8 \mu \mathrm{M})$ for $2 \mathrm{~h}$ for the detection of EGFR, Akt and Bad, and for $12 \mathrm{~h}$ for detection of Bax, Bak, Bcl-2, Bcl-xL, cIAP-1, cIAP-2, XIAP and survivin. Following treatment, cells $\left(1 \times 10^{7}\right.$ cells $\left./ \mathrm{ml}\right)$ were sedimented, then disrupted in lysis buffer containing $50 \mathrm{mM}$ Tris- $\mathrm{HCl}$ (pH 7.4), $300 \mathrm{mM} \mathrm{NaCl,} 5 \mathrm{mM}$ EDTA, $0.5 \%$ Triton X-100, with $100 \mathrm{mM}$ sodium o-vanadate and complete mini protease inhibitors (Roche Diagnostics, Mannheim, Germany). Lysates were clarified by centrifugation $\left(15 \mathrm{~min}, 14,000 \times \mathrm{g}\right.$ at $4^{\circ} \mathrm{C}$ ) and protein concentration measured using the Bradford assay. Proteins $(20 \mu \mathrm{g})$ were separated by SDS-PAGE, then transferred to Hybond PVDF membranes (Amersham Biosciences Corp., Piscataway, NJ). Membranes were blocked for 90 min in 5\% skim-milk blocking buffer at room temperature, then hybridized to a primary $\mathrm{Ab}$ (total anti-EGFR, -phosphoEGFR, -Akt, -phospho-Akt, -Bad, -phospho-Bad, -Bax, -Bak, -Bcl-2, -Bcl-xL, -cIAP-1, -cIAp-2, -XIAP, or -survivin), followed by an HRP-conjugated secondary Ab. Protein bands were visualized using the ECL Plus Western blot detection system (Amersham Biosciences). B-actin was used as a positive control. Immunoreactive bands were analyzed using a FluoroImager 595 and ImageQuant software (Amersham Biosciences). Background hybridization levels were subtracted from each sample, and protein abundances were normalized 
A

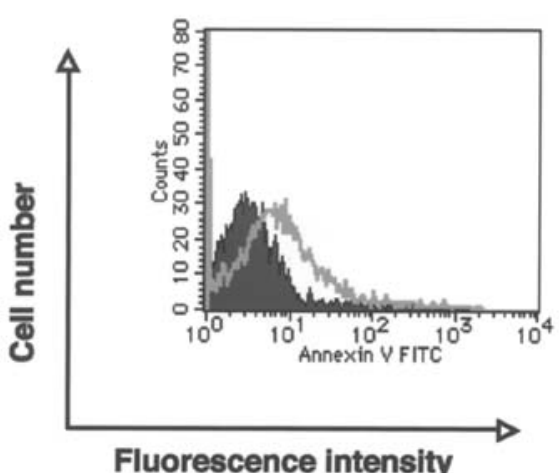

B

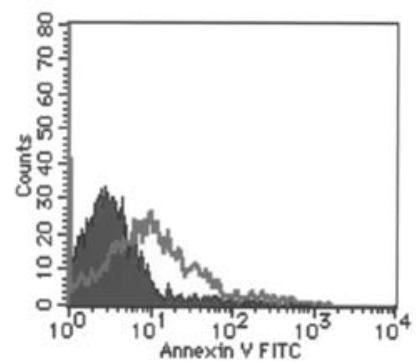

Figure 1. EGFR expression on NA and Ca9-22 cells. Expression of EGFR on (A) NA and (B) Ca9-22 cell membranes was determined using flow cytometry. All experiments were performed four times independently, and representative data are presented. Dark and bright lines represent control and experimental cells, respectively. Note that in all figures, dark lines are accompanied by black fill.

A
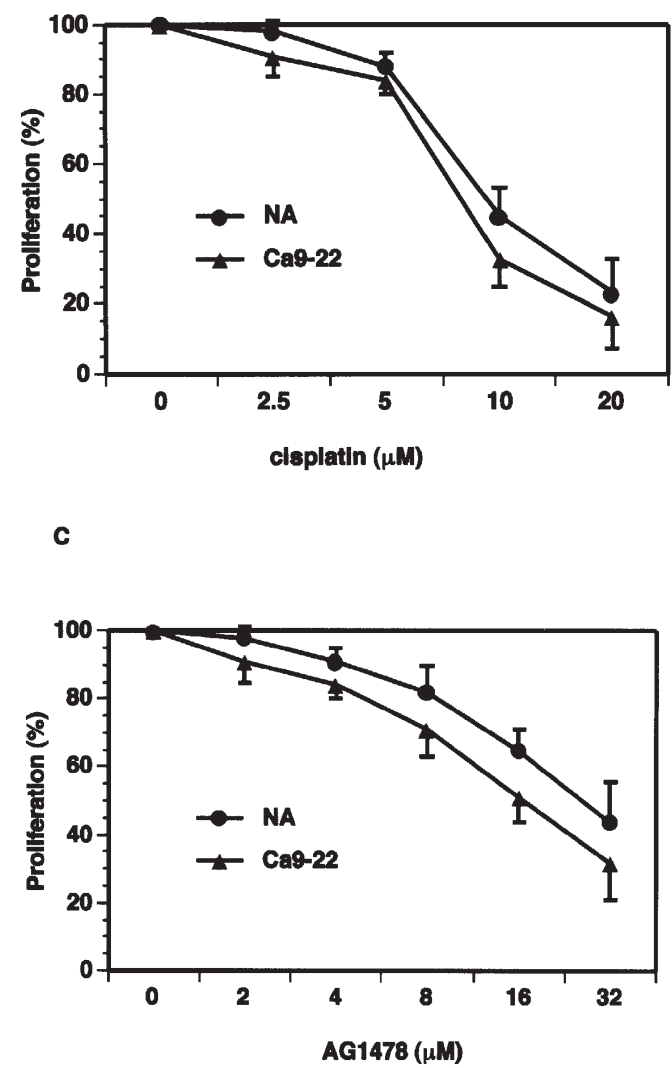

B

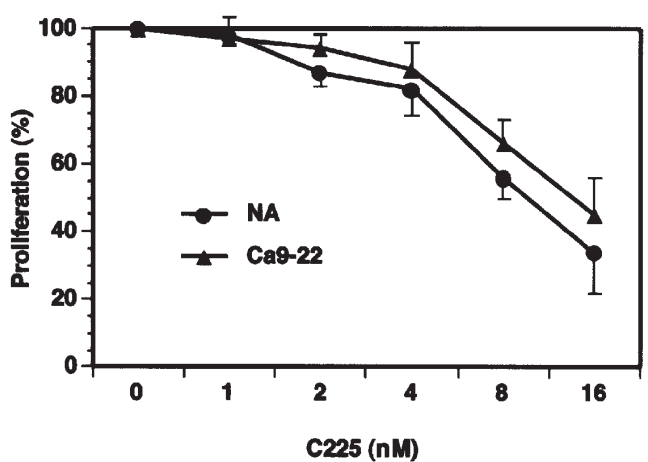

D

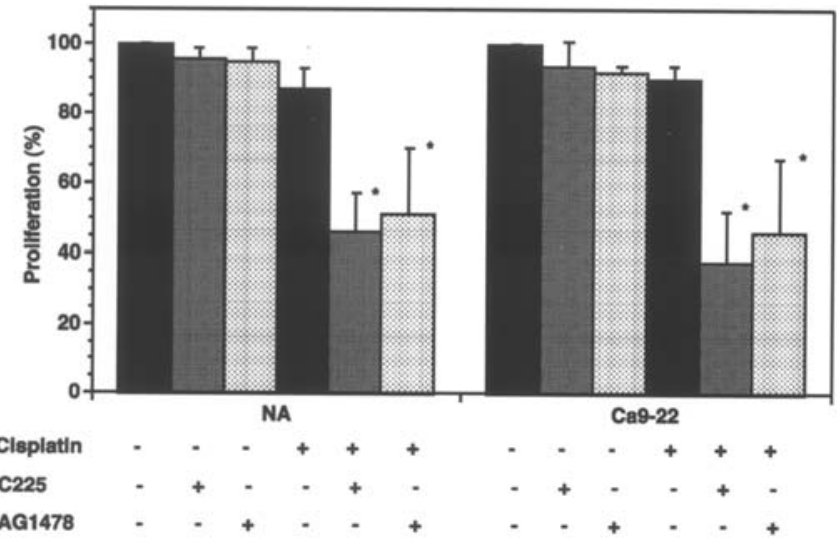

Figure 2. Effect of EGFR inhibitors and cisplatin on proliferation of OSCC cells. Proliferation of NA and Ca9-22 cells treated for 24 h with (A) cisplatin $(0-20 \mu \mathrm{M})$, (B) C225 (0-16 nM) or (C) AG1478 (0-32 $\mu \mathrm{M})$. (D) Bar graph comparing proliferation of NA and Ca9-22 cells treated with or without C225 $(4 \mathrm{nM})$ or AG1478 $(8 \mu \mathrm{M})$ for $2 \mathrm{~h}$, followed by incubation with or without cisplatin $(5 \mu \mathrm{M})$ for $24 \mathrm{~h}$. Data are expressed as the means $\pm \mathrm{SD}$ of four independent experiments. ${ }^{*} \mathrm{p}<0.05$, compared with untreated cells.

to those of $\beta$-actin for each sample. We normalized the results obtained for experimental proteins to those of the controls.

Statistical analysis. The values are presented as the means \pm SD. Data were analyzed using a One-way repeated measure ANOVA. $p<0.05$ was considered to be statistically significant.

\section{Results}

EGFR expression in OSCC cells. EGFR is expressed in SCC cells (14) and we examined its expression in OSCC cells using a FACScan flow cytometer. Constitutive EGFR expression was detected on both the NA and Ca9-22 cell lines (Fig. 1), suggesting that it plays a role in OSCC cells. 
A NA
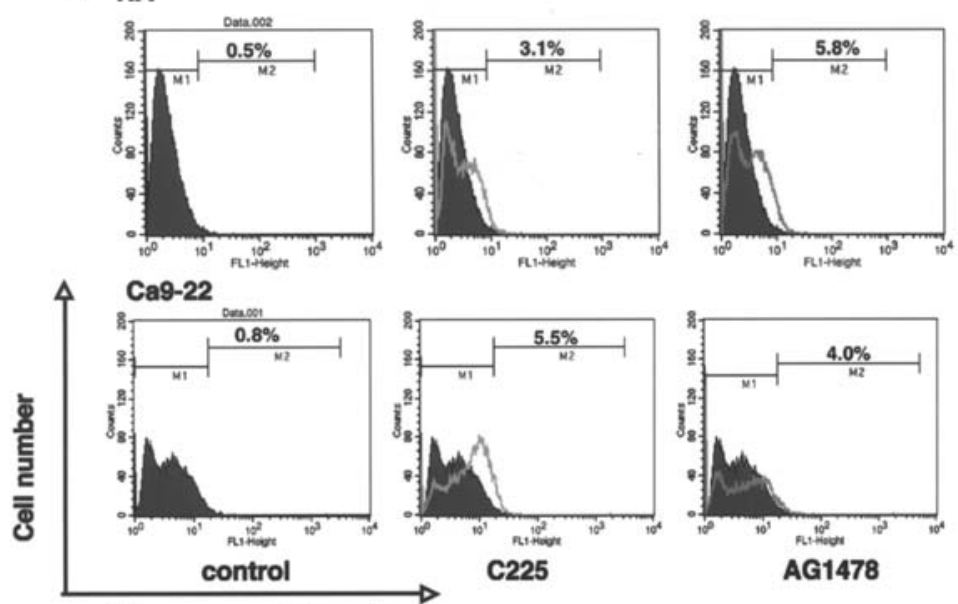

Fluorescence Intensity

B NA
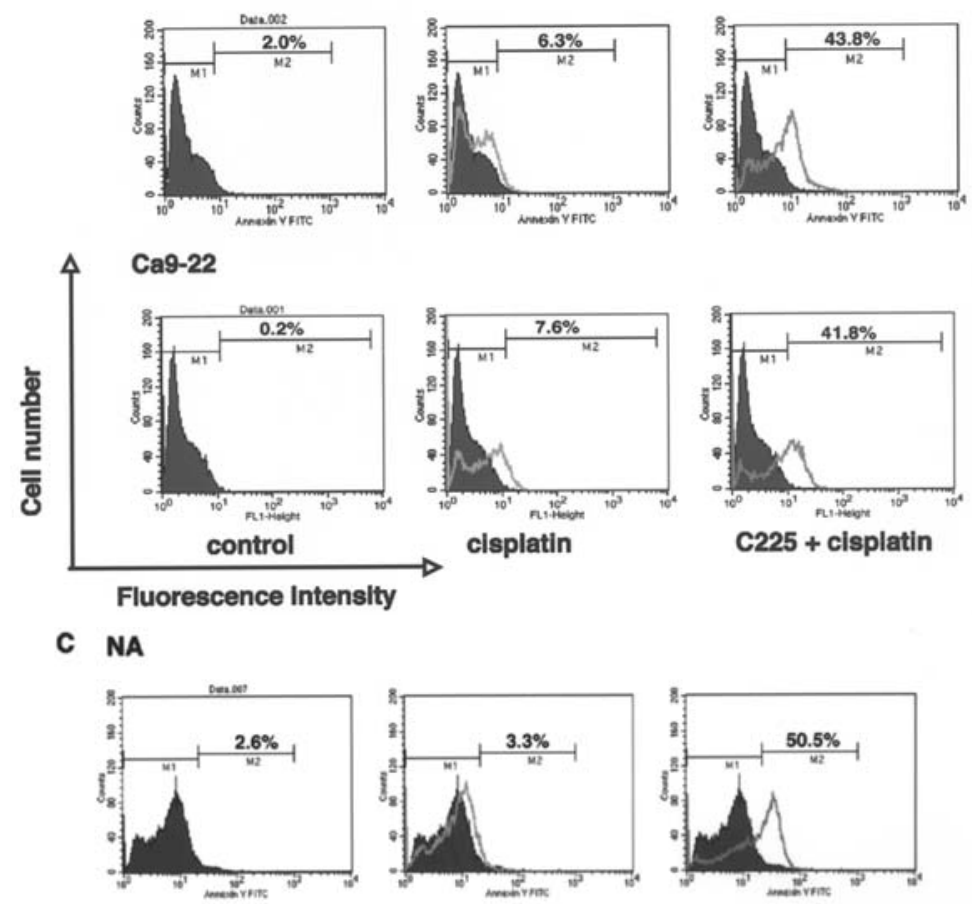

C225 + cisplatin
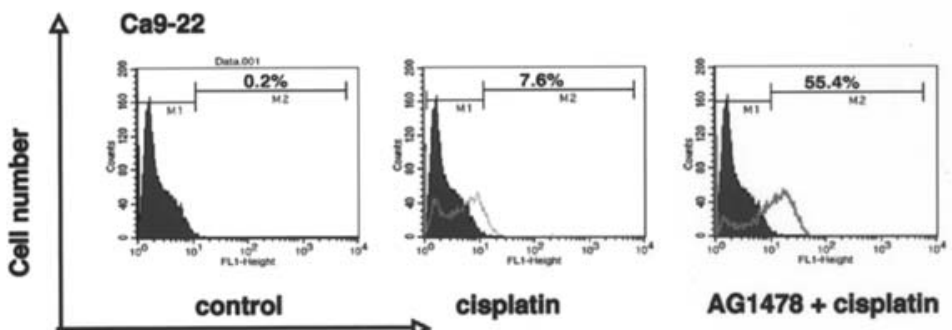

Fluorescence intensity

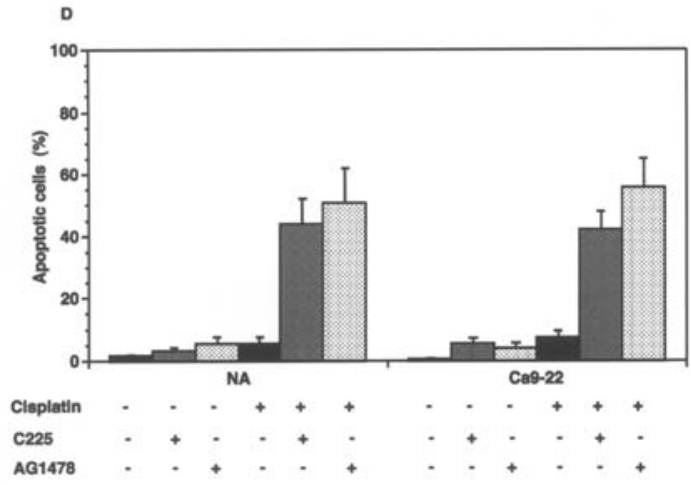

Figure 3. Effect of EGFR inhibitors on cisplatin-mediated apoptosis. NA (top panel) and Ca9-22 (lower panel) cells were treated with or without $\mathrm{C} 225(4 \mathrm{nM})$ or AG1478 $(8 \mu \mathrm{M})$ for $2 \mathrm{~h}$, followed by incubation with or without cisplatin $(5 \mu \mathrm{M})$ for $24 \mathrm{~h}$. All experiments were performed four times independently, and representative data are presented. Dark and bright lines represent untreated control and treated experimental cells, respectively. (A) EGFR inhibitor treatments. Untreated (left), C225-treated (middle) and AG1478 (right). (B) C225 and cisplatin treatment. Untreated (left), C225-treated (middle) and C225 with cisplatin-treated (right). (C) AG1478 and cisplatin treatment. Untreated (left), AG1478-treated (middle) and AG1478 with cisplatin-treated (right). (D) Bar graph comparing percentage apoptosis for the above treatments. Data are expressed as the means \pm SD of four independent experiments. ${ }^{*} \mathrm{p}<0.05$, compared with untreated cells. 


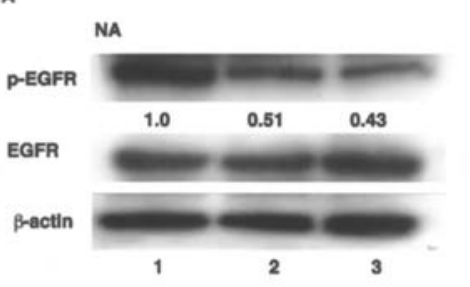

B

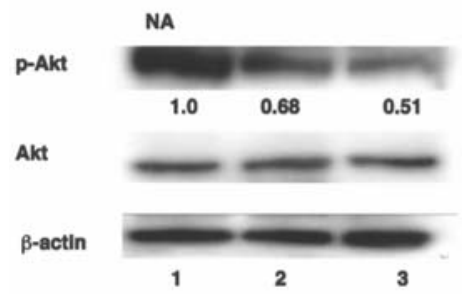

C

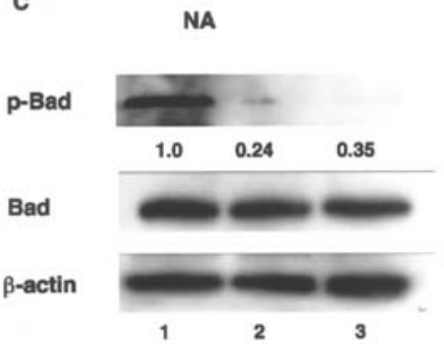

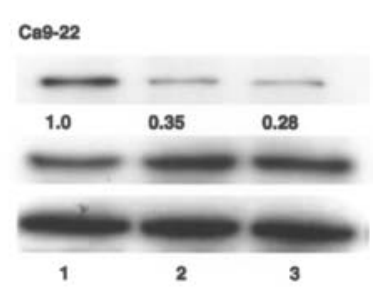
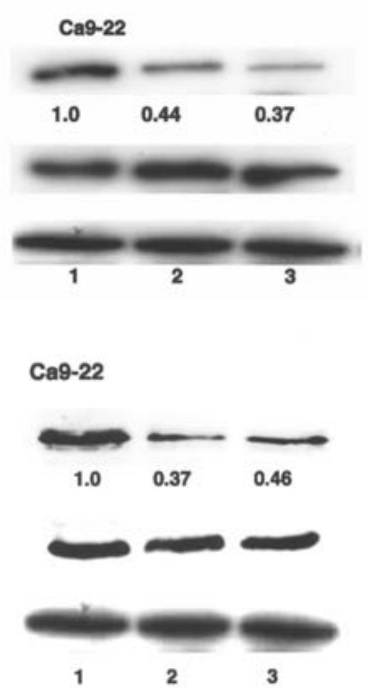

Figure 4. Effect of EGFR inhibitors on phosphorylation of EGFR, Akt and Bad. NA (left) and Ca9-22 (right) cells were treated with C225 (4 nM) or AG1478 $(8 \mu \mathrm{M})$ for $1 \mathrm{~h}$, after which they were harvested and protein expression was determined using Western blot analysis, as described in Materials and methods. All experiments were performed four times independently. Phosphorylation of (A) EGFR; (B) Akt; (C) Bad. Lane 1, untreated; lane 2, C225; lane 3, AG1478. The relative abundances of unphosphorylated to phosphorylated proteins were normalized to that of $\beta$-actin. Untreated controls were set as 1.0.

Effects of EGFR inhibitors on cisplatin-mediated antiproliferation. Cisplatin is the most commonly used agent for treatment of patients with SCC $(3,4)$. To determine whether or not a combination of EGFR inhibitors and cisplatin can alter the proliferation of OSCC cells, we treated the NA and Ca9-22 cell lines with a range of concentrations of cisplatin $(0-20 \mu \mathrm{M}), \mathrm{C} 225(0-16 \mathrm{nM})$ and AG1478 (0-32 $\mu \mathrm{M})$. Our results indicate that individually, all three compounds inhibited cell growth in a dose-dependent manner (Fig. 2A-C). We then examined the effects of combination treatment using fixed concentrations of each drug ( $4 \mathrm{nM} \mathrm{C225}$ or $8 \mu \mathrm{M}$ AG1478 with $5 \mu \mathrm{M}$ cisplatin). At these concentrations EGFR inhibitors and cisplatin alone were not cytotoxic, whereas a significant inhibition of proliferation was observed under the combination treatments (Fig. 2D).

Effects of EGFR inhibitors on cisplatin-mediated apoptosis. Cisplatin induces apoptosis in cancer cells (8-10) and to determine whether or not there is a change in the susceptibility of EGFR inhibitor-treated OSCC cells to cisplatin-mediated apoptosis, we examined annexin-V binding using a FACScan flow cytometer. As single agents, treatment with either C225 (4 $\mathrm{nM})$ or AG $1478(8 \mu \mathrm{M})$ effected $<10 \%$ apoptosis in OSCC cells (Fig. 3A); and at such low concentrations, these cells were relatively resistant to apoptosis. However, treatment

A

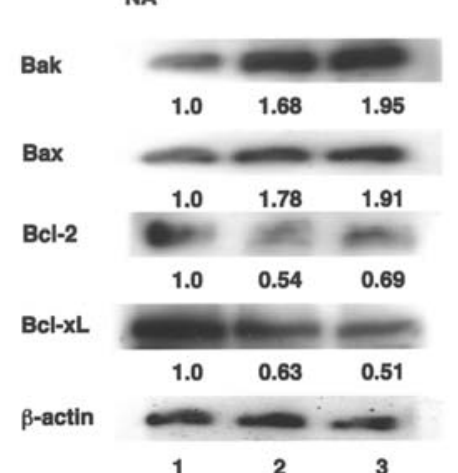

Ca9-22

B

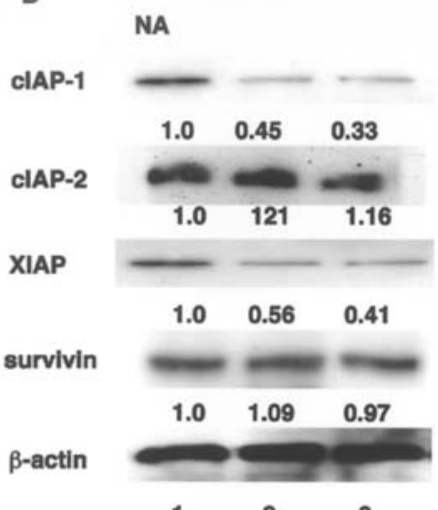

Ca9-22

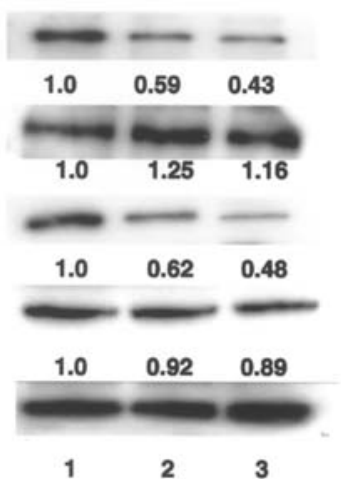

Figure 5. Effect of EGFR inhibitors on apoptosis-regulated protein expression. NA (left panel) and Ca9-22 (right panel) cells were treated with C225 (4 nM) or AG1478 $(8 \mu \mathrm{M})$ for $12 \mathrm{~h}$, after which they were harvested and apoptosisregulated protein expression was determined using Western blot analysis. All experiments were performed four times independently. Expression of (A) Bcl-2; and (B) IAP family proteins. Lane 1, control; lane 2, C225; lane 3, AG1478. The relative abundances of Bcl-2 and IAP family proteins were normalized to that of $\beta$-actin. Untreated controls were set as 1.0 .

with a combination of an EGFR inhibitor and cisplatin effected a greater induction of apoptosis than that achieved through the use of any of these agents alone (Fig. 3B-D).

Effects of EGFR inhibitors on phosphorylation of EGFR, Akt and Bad. To determine whether or not C225 and AG1478 can modulate activation of EGFR in NA and Ca9-22 cells, we examined EGFR phosphorylation using Western blot analysis. We observed that EGFR was phosphorylated constitutively in OSCC cells and became down-regulated in the presence of C225 (4 nM) and AG1478 (8 $\mu \mathrm{M})$ (Fig. 4A). Akt is an important signal transducer for cancer cell growth and can be regulated through the EGFR signaling pathway (29). We examined p-Akt/Akt in the presence or absence of EGFR inhibitors and observed that both C225 and AG1478 effected a marked reduction in p-Akt levels (Fig. 4B). Bad is a Bcl-2 family member, which binds to Bcl-2 or Bcl-xL and inhibits their anti-apoptotic activities. When Bad is phosphorylated by Akt, it does not exhibit pro-apoptotic activity and it is thought to be a direct target of Akt in promoting cell survival $(28,30)$. We observed that EGFR inhibitors strongly reduced the levels of p-Bad in OSCC cells (Fig. 4C). Thus, our results suggest that EGFR inhibitors can modulate survival in OSCC cells via reduction of p-Akt and p-Bad levels. 
Effects of EGFR inhibitors on expression of apoptosisregulating proteins. To elucidate the molecular mechanisms underlying the effects of treatment with EGFR inhibitors in OSCC cells, we examined the abundance of pro- and antiapoptotic proteins using Western blot analysis. Members of the Bcl-2 and IAP families play important roles in modulation of the intrinsic pathway (9). Treatment with C225 and AG1478 up-regulated levels of the pro-apoptotic proteins Bak and Bax, and down-regulated levels of the anti-apoptotic proteins Bcl-2 and Bcl-xL (Fig. 5A), as well as cIAP-1 and XIAP (Fig. 5B). However, no significant change in expression was observed for cIAP-2 or survivin (Fig. 5B). These results suggest that in OSCC cells, EGFR inhibitors can modulate cisplatinmediated apoptosis via expression of pro- and anti-apoptotic proteins.

\section{Discussion}

EGFR is expressed at high levels in SCC cells (14) and in this study we demonstrated that the cell lines NA and Ca9-22 both expressed EGFR (Fig. 1) and showed constitutive phosphorylation of EGFR and Akt (Fig. 4). The PI 3-K/Akt pathway is important for promoting survival/death of cells (29,31); it can be activated by EGFR signaling (29) and inactivated by EGFR inhibitors $(29,32)$. Constitutively-active Akt may be involved in cellular resistance to EGFR inhibitors such as cetuximab, gefinitib and erlotinib, and these inhibitors have been shown to reduce Akt phosphorylation in SCC cells (32-34). In the current study, we demonstrated that two EGFR inhibitors, C225 (anti-EGFR mAb) and AG1478 (EGFR-TK inhibitor) reduced phosphorylation of EGFR and Akt in OSCC cells (Fig. 4), suggesting that they can modulate cell survival via attenuation of EGFR and Akt activity.

Proliferation of OSCC cells was shown to be inhibited in a dose-dependent manner by cisplatin, C225 or AG1478. Interestingly, we observed a synergistic inhibition of growth when cells were treated with combinations of either C225 or AG1478 and sub-cytotoxic concentrations of cisplatin (Figs. 2 and 3). Moreover, our results indicated that this growth inhibition resulted primarily from induction of apoptosis. Previous studies have also shown that EGFR inhibitors can enhance the anti-tumor activities of cytotoxic agents such as cisplatin against SCC cells (21-25). However, the molecular mechanisms underlying the effects of treatment with EGFR inhibitors and cisplatin, such as inhibition of proliferation and enhancement of apoptosis, remain unclear. In most cancer cells, apoptosis is dependent upon the mitochondrial 'intrinsic' pathway, in which both caspase activation and activity are tightly controlled $(10,14)$. This process is regulated by pro- and anti-apoptotic proteins, such as members of the Bcl-2 and IAP families $(9,10)$. While members of the Bcl-2 family regulate the mitochondrial pathway prior to caspase activation, IAP proteins are believed to regulate apoptosis following activation (35). For examples, caspase-9 activation is inhibited by anti-apoptotic Bcl-2 family proteins such as $\mathrm{Bcl}-2$ and $\mathrm{Bcl}-\mathrm{xL}$, and facilitated by pro-apoptotic Bcl-2 family proteins such as Bax and Bak (36). In addition, active forms of caspase-3, $-6,-7$ and -9 can be inhibited by XIAP (35). Inhibition of cancer drug-induced apoptosis has been shown to depend upon the activation of intact caspase cascades
(37), and caspase-9 is the principal initiator caspase mediating cisplatin-induced apoptosis in SCCs of the head and neck (38). In cancer cells, overexpression of Bcl-2 (39), Bcl-xL (40) and XIAP (41) as well as mutations in Bax (42), have been observed and not only have cisplatin-resistant SCC cells been shown to overexpress Bcl-xL $(37,43)$ and Bcl-2 (44), they also fail to exhibit activation of caspase- 3 .

A variety of IAP antagonists significantly suppress the growth of numerous types of human solid tumors in vivo, and thus, represent novel prototypic anti-cancer drugs $(45,46)$. The results of this study suggest that pre-treatment of OSCC cells with EGFR inhibitors can modulate expression of Bcl-2 and IAP family proteins, leading to enhancement of cisplatinmediated apoptosis.

In the current study, C225 and AG1478 regulated the abundance of Bcl-2 family proteins in OSCC cells, reducing the levels of Bcl-2 and Bcl-xL and increasing those of Bax and Bak. This agrees with the findings of a previous study that demonstrated a concomitant increase in Bax expression and decrease in Bcl-2 expression following exposure of SCC cells to C225 (17). In various cancer cells, AG 1478 and gefitinib have been shown to induce expression of pro-apoptotic members of the Bcl-2 family such as Bak, Bax and Bim and to inhibit anti-apoptotic members such as Bcl-2 and Bcl-xL (47). This is the first report that EGFR TK inhibitors regulate expression of Bcl-2 family proteins in SCC cells. However, a study has indicated that EGFR inhibitors do not affect the levels of Bcl-2 family proteins (48). There are scant data concerning the effects of EGFR inhibitors on the regulation of IAP family proteins in cancer cells. We have shown that although the levels of cIAP-1 and XIAP were down-regulated by EGFR inhibitors, those of cIAP-2 and survivin were not. EGFR antagonists (gefitinib, erlotinib) reduce cIAP-2 expression in intestinal epithelial cells (49). Although EGFR activation did not affect XIAP levels in breast cancer cells (50), recent studies have shown that activation results in upregulation of survivin $(51,52)$. Therefore, further investigation is required to determine whether or not whether EGFR inhibitors can regulate the levels of IAP family proteins in different types of cancer cells.

Gefitinib prevents phosphorylation of Bad (53) and in this study we demonstrated that EGFR inhibitors (C225 and AG1478) could also reduce its phosphorylation levels in OSCC cells. Inactivated Bad binds to mitochondrial Bcl-2 and Bcl-xL, preventing cytochrome $\mathrm{c}$ release and caspase- 9 activation, and thus, inhibiting their anti-apoptotic activities (54). A number of studies have shown that the PI 3-K/Akt pathway also regulates the levels of Bcl-2 and IAP family proteins $(55,56)$, and we have demonstrated that EGFR inhibitors reduce Akt phosphorylation levels. In a previous study, we showed that the PI 3-K inhibitors wortmannin and LY294002 also inhibited Bad phosphorylation in OSCC cells (28). In SCCs, inhibition of Akt phosphorylation is coupled with a significant decrease in levels of the anti-apoptotic proteins Bcl-2 and Bcl-xL (57). The PI 3-K/Akt pathway can also inhibit the mitochondrial pathway $(58,59)$. Moreover, antisense molecules have been shown to reduce Bcl-2 (60) and XIAP (61) levels, sensitizing cancer cells to cisplatin-induced apoptosis.

In conclusion our studies demonstrate that in OSCC cells, EGFR inhibitors (anti-EGFR mAb and EGFR TK inhibitor) 
regulate expression of pro- and anti-apoptotic proteins, including members of the Bcl-2 and IAP families. We observed that cisplatin-mediated apoptosis was enhanced by co-treatment with EGFR inhibitors, and suggest that a combination therapy may provide novel therapeutic options for OSCC treatment. In general, EGFR inhibitors are well tolerated in clinical trials (21-25), whereas cisplatin induces a variety of severe toxic side effects. As the combinatorial treatment can achieve clinical efficacy using a low dose of cisplatin, it may overcome the challenges of cisplatin-related toxicity (5). In addition, these combinatorial regimens may be useful against patients that exhibit cisplatin resistance.

\section{References}

1. Forastiere AA, Koch W, Trotti A and Sidransky D: Head and neck cancer. N Engl J Med 345: 1890-1900, 2001.

2. Jefferies S and Foulkes WD: Genetic mechanisms in squamous cell carcinoma. Oral Oncol 37: 115-126, 2001.

3. Herskovic A, Martz K, al-Sarraf M, et al: Combined chemotherapy and radiotherapy compared with radiotherapy alone in patients with cancer of the esophagus. N Engl J Med 326: 1593-1598, 1992.

4. De Andres L, Brunet J, Lopez-Pousa A, et al: Randomized trial of neoadjuvant cisplatin and fluorouracil versus carboplatin and fluorouracil in patients with stage IV-M0 head and neck cancer. J Clin Oncol 13: 1493-1500, 1995.

5. Bourhis J: New approaches to enhance chemotherapy in SCCHN. Ann Oncol 16: 20-24, 2005.

6. Gonzalez VM, Fuertes MA, Alonso C and Perez JM: Is cisplatininduced cell death always produced by apoptosis? Mol Pharmacol 59: 657-663, 2001.

7. Eastman A: Activation of programmed cell death by anticancer agents: cisplatin as a model system. Cancer Cell 2: 275-280, 1990.

8. Gottesman MM: Mechanisms of cancer drug resistance. Annu Rev Med 53: 615-627, 2002.

9. Hersey $\mathrm{P}$ and Zhang XD: Overcoming resistance of cancer cells to apoptosis. J Cell Physiol 196: 9-18, 2003.

10. Kaufmann SH and Vaux DL: Alterations in the apoptotic machinery and their potential role in anticancer drug resistance. Oncogene 22: 7414-7430, 2003.

11. Mendelsohn J: Targeting the epidermal growth factor receptor for cancer therapy. J Clin Oncol 20: S1-S13, 2002.

12. Arteaga CL: Overview of epidermal growth factor receptor biology and its role as a therapeutic target in human neoplasia. Semin Oncol 29: S3-S9, 2002.

13. Shin DM, Ro JY, Hong WK and Hittelman WN: Dysregulation of epidermal growth factor receptor expression in premalignant lesions during head and neck tumorigenesis. Cancer Res 54: 3153-3159, 1994.

14. Rubin Grandis J, Melhem MF, Barnes EL and Tweardy DJ: Quantitative immunohistochemical analysis of transforming growth factor-alpha and epidermal growth factor receptor in patients with squamous cell carcinoma of the head and neck. Cancer 78: 1284-1292, 1996.

15. Kitagawa Y, Ueda M, Ando N, Ozawa S, Shimizu N and Kitajima M: Further evidence for prognostic significance of epidermal growth factor receptor gene amplification in patients with esophageal squamous cell carcinoma. Clin Cancer Res 2: 909-914, 1996.

16. Ang KK, Berkey BA, Tu X, et al: Impact of epidermal growth factor receptor expression on survival and pattern of relapse in patients with advanced head and neck carcinoma. Cancer Res 62: 7350-7356, 2002.

17. Huang SM, Bock JM and Harari PM: Epidermal growth factor receptor blockade with $\mathrm{C} 225$ modulates proliferation, apoptosis, and radiosensitivity in squamous cell carcinomas of the head and neck. Cancer Res 59: 1935-1940, 1999.

18. Herbst RS and Shin DM: Monoclonal antibodies to target epidermal growth factor receptor-positive tumors: a new paradigm for cancer therapy. Cancer 94: 1593-1611, 2002.

19. Cohen EE, Rosen F, Stadler WM, et al: Phase II trial of ZD1839 in recurrent or metastatic squamous cell carcinoma of the head and neck. J Clin Oncol 21: 1980-1987, 2003.
20. Soulieres D, Senzer NN, Vokes EE, Hidalgo M, Agarwala SS and Siu LL: Multicenter phase II study of erlotinib, an oral epidermal growth factor receptor tyrosine kinase inhibitor, in patients with recurrent or metastatic squamous cell cancer of the head and neck. J Clin Oncol 22: 77-85, 2004.

21. Baselga J, Pfister D, Cooper MR, et al: Phase I studies of antiepidermal growth factor receptor chimeric antibody $\mathrm{C} 225$ alone and in combination with cisplatin. J Clin Oncol 18: 904-914, 2000 .

22. Bianco C, Tortora G, Bianco R, et al: Enhancement of antitumor activity of ionizing radiation by combined treatment with the selective epidermal growth factor receptor-tyrosine kinase inhibitor ZD1839 (Iressa). Clin Cancer Res 8: 3250-3258, 2002.

23. Magne N, Fischel JL, Tiffon C, et al: Molecular mechanisms underlying the interaction between ZD1839 ('Iressa') and cisplatin/5-fluorouracil. Br J Cancer 89: 585-592, 2003.

24. Herbst RS, Arquette M, Shin DM, et al: Phase II multicenter study of the epidermal growth factor receptor antibody cetuximab and cisplatin for recurrent and refractory squamous cell carcinoma of the head and neck. J Clin Oncol 23: 5578-5587, 2005.

25. Pfister DG, Su YB, Kraus DH, et al: Concurrent cetuximab, cisplatin, and concomitant boost radiotherapy for locoregionally advanced, squamous cell head and neck cancer: a pilot phase II study of a new combined-modality paradigm. J Clin Oncol 24: 1072-1078, 2006

26. Watanabe $H$, Iwase $M$, Ohashi $M$ and Nagumo $M$ : Role of interleukin-8 secreted from human oral squamous cell carcinoma cell lines. Oral Oncol 38: 670-679, 2002.

27. Iwase M, Watanabe $H$, Kondo G, Ohashi $M$ and Nagumo $M$ : Enhanced susceptibility of oral squamous cell carcinoma cell lines to Fas-mediated apoptosis by cisplatin and 5-fluorouracil. Int J Cancer 106: 619-625, 2003.

28. Kondo G, Iwase M, Watanabe H, et al: Enhancement of susceptibility to Fas-mediated apoptosis in oral squamous cell carcinoma cells by phosphatidylinositol 3-kinase inhibitor. Oral Oncol 42: 745-752, 2006.

29. Bancroft CC, Chen Z, Yeh J, et al: Effects of pharmacologic antagonists of epidermal growth factor receptor, PI3K and MEK signal kinases on $\mathrm{NF}-\kappa \mathrm{B}$ and $\mathrm{Ap}-1$ activation and IL- 8 and VEGF expression in human head and neck squamous cell carcinoma lines. Int J Cancer 99: 538-548, 2002.

30. Datta SR, Dudek H, Tao X, et al: Akt phosphorylation of BAD couples survival signals to the cell-intrinsic death machinery. Cell 91: 231-241, 1997.

31. Datta SR, Brunet A and Greenberg ME: Cellular survival: a play in three Akts. Genes Dev 13: 2905-2927, 1999.

32. Huang S, Armstrong EA, Benavente S, Chinnaiyan P and Harari PM: Dual-agent molecular targeting of the epidermal growth factor receptor (EGFR): combining anti-EGFR antibody with tyrosine kinase inhibitor. Cancer Res 64: 5355-5362, 2004.

33. Chakravarti A, Loeffler JS and Dyson NJ: Insulin-like growth factor receptor I mediates resistance to anti-epidermal growth factor receptor therapy in primary human glioblastoma cells through continued activation of phosphoinositide 3-kinase signaling. Cancer Res 62: 200-207, 2002.

34. Janmaat ML, Kruyt FA, Rodriguez JA and Giaccone G: Response to epidermal growth factor receptor inhibitors in non-small cell lung cancer cells: limited antiproliferative effects and absence of apoptosis associated with persistent activity of extracellular signal-regulated kinase or Akt kinase pathway. Clin Cancer Res 9: 2316-2326, 2003.

35. Salvesen GS and Duckett CS: IAP proteins: blocking the road to death's door. Nat Rev Mol Cell Biol 3: 401-410, 2002.

36. Cory S and Adams JM: The Bcl2 family: regulators of the cellular life-or-death switch. Nat Rev Cancer 2: 647-656, 2002.

37. Kojima H, Endo K, Moriyama H, et al: Abrogation of mitochondrial cytochrome c release and caspase- 3 activation in acquired multidrug resistance. J Biol Chem 273: 16647-16650, 1998.

38. Kuwahara D, Tsutsumi K, Kobayashi T, Hasunuma T and Nishioka K: Caspase-9 regulates cisplatin-induced apoptosis in human head and neck squamous cell carcinoma cells. Cancer Lett 148: 65-71, 2000.

39. Reed JC: Regulation of apoptosis by bcl-2 family proteins and its role in cancer and chemoresistance. Curr Opin Oncol 7: 541-546, 1995.

40. Catlett-Falcone R, Landowski TH, Oshiro MM, et al: Constitutive activation of Stat 3 signaling confers resistance to apoptosis in human U266 myeloma cells. Immunity 10: 105-110, 1999. 
41. Vucic D, Stennicke HR, Pisabarro MT, Salvesen GS and Dixit VM: ML-IAP, a novel inhibitor of apoptosis that is preferentially expressed in human melanomas. Curr Biol 10: 1359-1366, 2000.

42. Kasof GM and Gomes BC: Livin, a novel inhibitor of apoptosis protein family member. J Biol Chem 276: 3238-3246, 2001.

43. Noutomi T, Chiba H, Itoh M, Toyota H and Mizuguchi J: Bcl-x(L) confers multi-drug resistance in several squamous cell carcinoma cell lines. Oral Oncol 38: 41-48, 2002.

44. Johnstone RW, Ruefli AA and Lowe SW: Apoptosis: a link between cancer genetics and chemotherapy. Cell 108: 153-164, 2002.

45. Hu Y, Cherton-Horvat G, Dragowska V, et al: Antisense oligonucleotides targeting XIAP induce apoptosis and enhance chemotherapeutic activity against human lung cancer cells in vitro and in vivo. Clin Cancer Res 9: 2826-2836, 2003.

46. Schimmer AD, Welsh K, Pinilla C, et al: Small-molecule antagonists of apoptosis suppressor XIAP exhibit broad antitumor activity. Cancer Cell 5: 25-35, 2004.

47. Kurebayashi J, Okubo S, Yamamoto Y, et al: Additive antitumor effects of gefitinib and imatinib on anaplastic thyroid cancer cells. Cancer Chemother Pharmacol 58: 460-470, 2006.

48. Ariyama H, Qin B, Baba E, et al: Gefitinib, a selective EGFR tyrosine kinase inhibitor, induces apoptosis through activation of Bax in human gallbladder adenocarcinoma cells. J Cell Biochem 97: 724-734, 2006.

49. Liu Z, Li H, Derouet M, et al: ras oncogene triggers upregulation of cIAP2 and XIAP in intestinal epithelial cells: epidermal growth factor receptor-dependent and -independent mechanisms of ras-induced transformation. J Biol Chem 280: 37383-37392, 2005.

50. Peng XH, Karna P, Cao Z, Jiang BH, Zhou M and Yang L: Cross-talk between epidermal growth factor receptor and HIF-1a signal pathways increases resistance to apoptosis by upregulating survivin gene expression. J Biol Chem 281: 25903-25914, 2006.

51. Peng XH, Cao ZH, Xia JT, et al: Real-time detection of gene expression in cancer cells using molecular beacon imaging: new strategies for cancer research. Cancer Res 65: 1909-1917, 2005.
52. Asanuma H, Torigoe T, Kamiguchi K, et al: Survivin expression is regulated by coexpression of human epidermal growth factor receptor 2 and epidermal growth factor receptor via phosphatidylinositol 3-kinase/AKT signaling pathway in breast cancer cells. Cancer Res 65: 11018-11025, 2005.

53. Gilmore AP, Valentijn AJ, Wang P, et al: Activation of BAD by therapeutic inhibition of epidermal growth factor receptor and transactivation by insulin-like growth factor receptor. J Biol Chem 277: 27643-27650, 2002.

54. Hayakawa J, Ohmichi M, Kurachi H, et al: Inhibition of BAD phosphorylation either at serine 112 via extracellular signalregulated protein kinase cascade or at serine 136 via Akt cascade sensitizes human ovarian cancer cells to cisplatin. Cancer Res 60: 5988-5994, 2000

55. Chen X, Thakkar H, Tyan F, et al: Constitutively active Akt is an important regulator of TRAIL sensitivity in prostate cancer. Oncogene 20: 6073-6083, 2001.

56. Nesterov A, Lu X, Johnson M, Miller GJ, Ivashchenko Y and Kraft AS: Elevated AKT activity protects the prostate cancer cell line LNCaP from TRAIL-induced apoptosis. J Biol Chem 276: 10767-10774, 2001

57. Sharma H, Sen S and Singh N: Molecular pathways in the chemosensitization of cisplatin by quercetin in human head and neck cancer. Cancer Biol Ther 4: 949-955, 2005.

58. Vianco I and Sawyers CL: The phosphatidylinositol 3-kinase AKT pathway in human cancer. Nat Rev Cancer 2: 489-501, 2002.

59. Luo J, Manning BD and Cantley LC: Targeting the PI3K-Akt pathway in human cancer: rationale and promise. Cancer Cell 4: 257-262, 2003.

60. Campos L, Sabido O, Rouault JP and Guyotat D: Effects of BCL-2 antisense oligodeoxynucleotides on in vitro proliferation and survival of normal marrow progenitors and leukemic cells. Blood 84: 595-600, 1994.

61. Li J, Feng Q, Kim JM, et al: Human ovarian cancer and cisplatin resistance: possible role of inhibitor of apoptosis proteins. Endocrinology 142: 370-380, 2001. 